\title{
Words of Caution Regarding Adjustable Gastric Band Tubing
}

\author{
Christopher Starnes, MD, Sheilendra S. Mehta, MD, Peter A. Walker, MD, Kulvinder S. Bajwa, MD, \\ Erik B. Wilson, MD, Shinil K. Shah, DO \\ Department of Surgery, University of Texas Medical School, Houston, TX (all authors). \\ Michael E. DeBakey Institute for Comparative Cardiovascular Science and Biomedical Devices, Texas A\&M University, \\ College Station, TX (Dr Shah).
}

\begin{abstract}
Introduction: With the decreasing popularity of adjustable gastric band (AGB) placement and the increase in explants of the devices, for erosion, slips, or inadequate weight loss, in performing revisional surgery, it is of vital importance for surgeons to understand the problems that may arise during removal. This case involved an uncommonly reported complication of fractured band tubing resulting in incomplete removal of the tubing during revisional bariatric surgery, with reoperation necessary for complete removal. In the course of the procedure, a small-bowel tumor was identified.

Case Description: We present a 35-year-old woman who underwent conversion of a laparoscopic AGB to a sleeve gastrectomy. Failure to recognize a fracture in the band tubing resulted in retained tubing and readmission secondary to abdominal pain. During reoperation to remove the retained tubing, a small-bowel gastrointestinal stromal tumor (GIST) was incidentally identified and resected.
\end{abstract}

Discussion: This case highlights a rarely reported complication of fractured gastric band tubing, resulting in incomplete removal of the tubing during revisional surgery, with the incidental discovery of a GIST in the small bowel.

Key Words: Adjustable gastric band, Gastrointestinal stromal tumor, Re-operative surgery, Revisional bariatric surgery.

Citation Starnes C, Mehta SS, Walker PA, Bajwa KS, Wilson EB, Shah SK. Words of Caution Regarding Adjustable Gastric Band Tubing CRSLS e2015.00017. DOI: 10.4293/CRSLS.2015.00017.

Copyright $(0) 2015$ by SLS, Society of Laparoendoscopic Surgeons. This is an open-access article distributed under the terms of the Creative Commons Attribution-Noncommercial-ShareAlike 3.0 Unported license, which permits unrestricted noncommercial use, distribution, and reproduction in any medium, provided the original author and source are credited.

Disclosure: Dr. Wilson has served as a consultant to Intuitive Surgical, Ethicon, Gore, Apollo Endosurgery, and Olympus.

Drs Starnes and Mehta contributed equally to this work.

Address correspondence to: Peter A. Walker, MD, Department of Surgery, University of Texas Medical School at Houston, 6431 Fannin Street, Houston, TX 77030.

Telephone: 713-632-4558, Fax: 713-383-3708, E-mail: peter.a.walker@uth.tmc.edu

\section{INTRODUCTION}

Although the popularity of laparoscopic adjustable gastric band (AGB) placement has decreased in recent years, it is vital for the gastrointestinal surgeon to understand the potential complications of AGBs, given the number of patients who have undergone this procedure and the increasing number of such patients returning for removal, revision, or both. The authors present a rare case of a patient who underwent removal of an AGB and conversion to a sleeve gastrectomy. After the revision, the patient reported abdominal pain, and retained gastric band tubing was discovered on radiography, prompting reoperation. A small-bowel gastrointestinal stromal tumor (GIST) was found during the second operation. We discuss bandrelated complications during revisional bariatric surgery and the cases in the literature of incidental discovery of GISTs in patients undergoing bariatric surgery.

\section{CASE REPORT}

The patient was a 35-year-old woman with morbid obesity (body mass index, 38.6), who presented electively for revisional bariatric surgery. She had undergone placement of a laparoscopic AGB (Lap Band, Allergan, Irvine, CA) approximately six years before presentation. She was ex- 
periencing moderate reflux secondary to a slipped band, as confirmed by endoscopy and upper gastrointestinal study. In addition, the band was not holding fluid, secondary to a presumed small leak in the band or tubing. Plain films and computed tomography (CT) of the abdomen revealed no disruption of the AGB tubing or system.

The patient underwent successful robot-assisted laparoscopic AGB removal with conversion to sleeve gastrectomy. The band and associated capsule were carefully dissected, and the band was unbuckled and removed from the stomach. The gastrogastric plication sutures were taken down. The band tubing was cut, and the band was removed through a $15-\mathrm{mm}$ accessory port. The subcutaneous port and associated tubing were removed via an incision directly over the port. The sleeve gastrectomy was created over a 32 French bougie. There were no intraoperative or postoperative events. An upper gastrointestinal swallow study performed on postoperative day 1 revealed no extravasation, obstruction, or leak. The patient began consuming a clear liquid diet and was discharged the following day with results in laboratory tests and vital signs with normal ranges. Pathology from the initial operation confirmed removal of a $5-\mathrm{cm}$ intact band, along with a $2.5-\mathrm{cm}$ white metallic port with an attached $11-\mathrm{cm}$ segment of white tubing, consistent with an explanted laparoscopically placed AGB.

The patient returned to the hospital on postoperative day 11 with nausea, emesis, abdominal pain, and constipation. She was afebrile, with tenderness in the left lower quadrant and a normal white blood cell count. A plain abdominal film revealed what appeared to be retained gastric band tubing and several nonspecific air-filled loops of proximal jejunum (Figure 1). The patient was informed of this finding and was taken to the operating room for a diagnostic laparoscopy. The tubing was found underneath the omentum along the left lateral abdominal wall and was easily removed. It was noted to have eroded through at the metal connector. Upon exploration, we noted erythematous and thickened loops of proximal jejunum. When we ran the small bowel, we found an approximately $3-\mathrm{cm}$ solid mass on the mesenteric border of the jejunum (Figure 2) and performed an extracorporeal small-bowel resection with anastomosis. The patient made an uneventful recovery after the second operation and was discharged on postoperative day 4. Pathology confirmed a GIST $(3.5 \times 3 \times 3 \mathrm{~cm})$. The lesion was cKit (CD117) positive. Desmin, muscle-specific actin, synaptophysin, chromogranin, and CD56 and CD34 markers were all negative. The mitotic rate was low (1/20 per highpower field), and all margins were negative (pT2 staging).
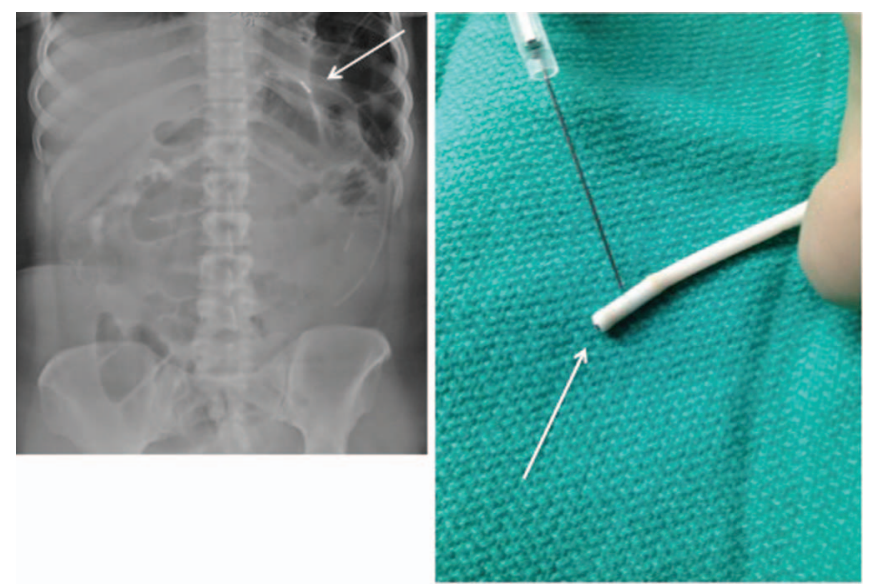

Figure 1. Plain abdominal radiograph demonstrates nonspecific dilation of colon and left upper quadrant jejunal loops. A foreign body appearing to represent retained gastric band tubing was noted along the left abdomen (arrow, left panel). The retained gastric band tubing was found along the left abdomen underneath the omentum. Cracks were seen in the tubing (needle, right panel), and it was noted to have eroded at the point of the metal connector (arrow, right panel).

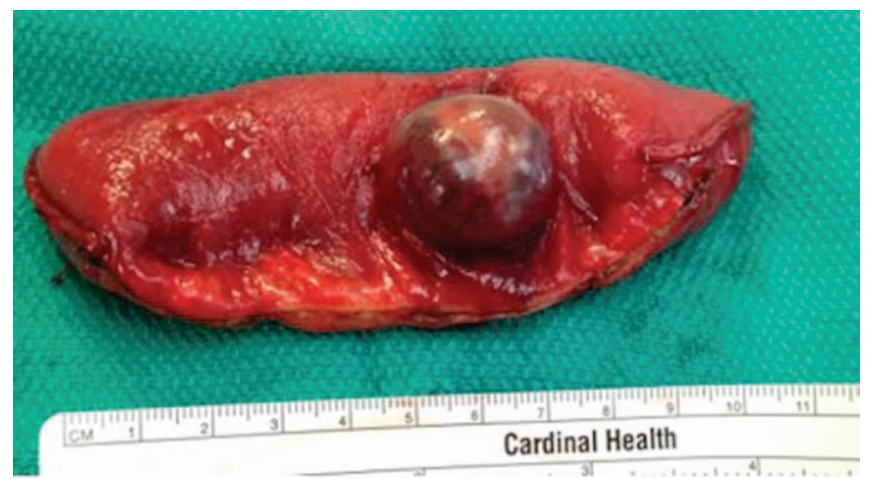

Figure 2. An approximately $3-\mathrm{cm}$ mesenteric mass was unexpectedly found in the proximal jejunum. On opening the antimesenteric side of the jejunum after resection, the submucosal mass was visible. Pathology confirmed a GIST

\section{DISCUSSION}

Commonly reported complications of AGBs include slippage, erosion, and lack of adequate weight loss. Complications related to band tubing are rarely reported, and most of what is reported centers around disconnection of the tube and port. ${ }^{1}$ Other complications include bowel obstruction, ${ }^{2}$ internal hernia, ${ }^{3}$ and erosion of tubing into the intestine and other organs. ${ }^{4}$

Problems leading to cracks or breakage in the connecting tubing have been reported, mostly presenting as leaks in 
the tubing. Lyass et $a^{5}$ studied a series of 270 patients who underwent AGB placement, of which 13 (5\%) underwent reoperation for port- or tubing-related complications; 6 of the cases were reported to involve a crack at the connection of the tubing to the port. ${ }^{5}$ Lattuada et al. ${ }^{6}$ published a series of 489 patients who underwent AGB placement with either the Lap Band system (Allergan, Irvine, CA) or the Heliogast system (Helioscopie, Lyon, France). Fiftyfour of those patients (11\%) had a leak in the band system, and $47 \mathrm{had}$ a crack near or at the metallic connector, as was the case in our patient.

During removal, careful examination of all explanted components of the AGB is vital. The explanted parts should fit together. In patients who have AGBs with metallic connectors, it is important to confirm that the metallic connector has been removed (Figure 3). Abnormally short connecting tubing should prompt examination for missed or retained tubing. In cases in which there is doubt, intraoperative radiography should be performed.

The discovery of a GIST in this patient was by accident. The incidence of these tumors in the United States is estimated to be between 3000 and 6000 cases per anum. The stomach is by far the most prevalent location of primary GISTs and most are identified in patients over the

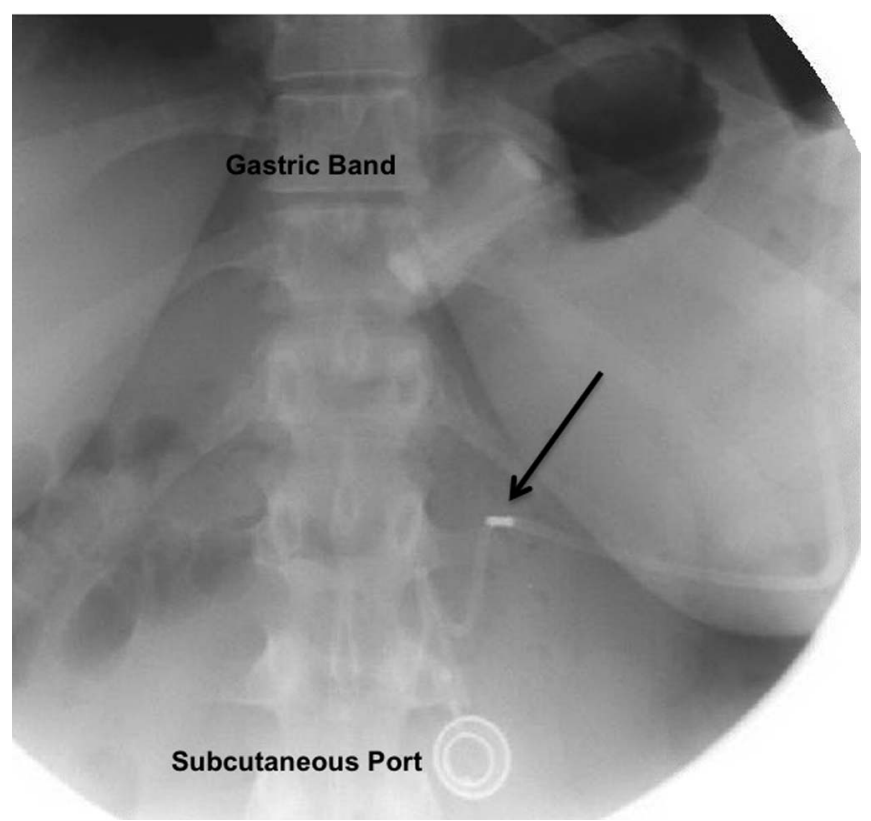

Figure 3. Representative radiograph demonstrating an AGB with metallic connector (arrow) attaching the subcutaneous port to the tubing of the gastric band. It is especially important to verify explantation of this segment of tubing during AGB removal. age of $50 . .^{7}$ In bariatric surgery, a sleeve gastrectomy is the only procedure that routinely involves removal of part of the gastrointestinal tract. Yuval et $\mathrm{al}^{8}$ evaluated $827 \mathrm{pa}-$ tients who underwent laparoscopic sleeve gastrectomy. Five had a GIST identified on final pathology. Surprisingly, none of the tumors was identified by preoperative esophagogastroduodenoscopy (EGD). Moreover, the tumors were low grade, located in the proximal sleeve, and more likely to be anterior. ${ }^{8}$ There is one other report of incidental discovery of a GIST noted during sleeve gastrectomy. ${ }^{9}$ Sanchez et al ${ }^{10}$ reported that 4 of 517 patient undergoing laparoscopic Roux-en-Y gastric bypass at their institution had GISTs that were found incidentally. Again, the tumors were located in the proximal third of the stomach on the anterior surface. Leuratti et al. ${ }^{11}$ reported removal of an incidentally noted 4.5 -cm GIST in the antrum of the stomach (not noted on preoperative endoscopy) during laparoscopic Roux-en-Y gastric bypass.

Most incidental GISTs discovered during bariatric surgery are found in the proximal stomach and almost uniformly have low malignancy potential. Furthermore, the tumors discovered in the literature were never visualized on preoperative upper endoscopy. If presumed GISTs are identified at the time of bariatric surgery, they should be excised with histologically negative margins. Care should be taken not to disrupt the pseudocapsule, to avoid tumor dissemination. Moreover, the tumor should be removed in a specimen-retrieval bag to avoid port-site seeding. For tumors with very low potential for malignant disease, adjuvant imatinib is generally unnecessary, unless highrisk features are noted on pathology. The current National Comprehensive Cancer Network (NCCN) guidelines for GISTs (with the exception of those $<2 \mathrm{~cm}$ ) recommend history and physical examination along with CT of the abdomen and pelvis, with contrast every 3 to 6 months for 5 years and then annually thereafter. ${ }^{12}$ Small-bowel GISTs can be removed with small-bowel resection and primary anastomosis. There is no need for lymph node harvest, as the tumor behaves like a sarcoma. ${ }^{7}$

\section{CONCLUSION}

This is a peculiar case with several important lessons to be learned. In retrospect, the patient's AGB system was not holding fluid, secondary to a presumed leak in the system. At the initial revision, the tubing was not noted to be disconnected from the port, and no gross breaks in the tubing were seen.

The case involved luck and diligence on the part of the surgical team. As the popularity of sleeve gastrectomy 
increases, we are likely to see more incidental discovery of GISTs in the bariatric population. It is imperative that all patients receive adjuvant therapy if necessary or are enrolled in a surveillance program. In addition, an understanding of the various gastric bands, both past and present, will enable the astute surgeon to identify and ensure complete removal of the AGB and its related components.

\section{References:}

1. Himpens J, Cadiere GB, Bazi M, Vouche M, Cadiere B, Dapri G. Long-term outcomes of laparoscopic adjustable gastric banding. Arch Surg. 2011;146:802-807.

2. Oppliger F, Wiedmaier G, Leon J. Acute small bowel obstruction due to the connecting tube of a gastric band. Surg Obes Relat Dis. 2014;10:e77-e79.

3. Ng MK, Thompson G. Laparoscopic adjustable gastric band tubing: unusual cause of an internal hernia. Surg Obes Relat Dis. 2009;5:517-518.

4. Cintolo JA, Levine MS, Huang S, Dumon K. Intraluminal erosion of laparoscopic gastric band tubing into duodenum with recurrent port-site infections. J Laparoendosc Adv Surg Tech A. 2012;22:591-594.

5. Lyass S, Cunneen SA, Hagiike M, et al. Device-related reoperations after laparoscopic adjustable gastric banding. Am Surg. $2005 ; 71: 738-743$.
6. Lattuada E, Zappa MA, Mozzi E, Antonini I, Boati P, Roviaro GC. Injection port and connecting tube complications after laparoscopic adjustable gastric banding. Obes Surg. 2010;20:410414.

7. De Vogelaere K, Hoorens A, Haentjens P, Delvaux G. Laparoscopic versus open resection of gastrointestinal stromal tumors of the stomach. Surg Endosc. 2013;27:1546-1554.

8. Yuval JB, Khalaileh A, Abu-Gazala M, et al. The true incidence of gastric GIST: a study based on morbidly obese patients undergoing sleeve gastrectomy. Obes Surg. 2014;24: 2134-2137.

9. Beltran MA, Pujado B, Mendez PE, et al. Gastric gastrointestinal stromal tumor (GIST) incidentally found and resected during laparoscopic sleeve gastrectomy. Obes Surg. 2010;20:393396.

10. Sanchez BR, Morton JM, Curet MJ, Alami RS, Safadi BY. Incidental finding of gastrointestinal stromal tumors (GISTs) during laparoscopic gastric bypass. Obes Surg. 2005;15:1384-1388.

11. Leuratti L, Alfa-Wali M, Bonanomi G. Intraoperative findings during a gastric bypass necessitating the removal of the gastric remnant: to proceed or not with the elective plan? Surg Obes Relat Dis. 2013;9:e69-e71.

12. National Comprehensive Cancer Network. Gastrointestinal Stromal Tumors (GIST). Available at http://www.nccn.org/professionals/physician_gls/pdf/sarcoma.pdf. Enrollment required. Accessed August 24, 2014. 